\title{
Prognostic analysis of salvage esophagectomy after definitive chemoradiotherapy for esophageal squamous cell carcinoma: The importance of lymphadenectomy
}

\author{
Shaohua Wang, MD, ${ }^{\text {ab }}$ Yuji Tachimori, MD, ${ }^{\text {a }}$ Nobukazu Hokamura, MD, ${ }^{a}$ Hiroyasu Igaki, MD, ${ }^{a}$ \\ Hidetsugu Nakazato, MD, ${ }^{\mathrm{a}}$ and Takayoshi Kishino, $\mathrm{MD}^{\mathrm{a}}$
}

\begin{abstract}
Objectives: The objective of this study was to review the prognostic factors for increased survival after salvage esophagectomy after definitive chemoradiotherapy for esophageal squamous carcinoma and determine the importance of lymphadenectomy from a prognostic view.
\end{abstract}

\begin{abstract}
Methods: Clinical data for all patients from January 1999 to December 2012 who underwent salvage esophagectomy for residual tumor or tumor recurrence after definitive chemoradiotherapy were retrospectively collected. Survival was determined and prognostic factors were analyzed with univariate and multivariate analyses.
\end{abstract}

\begin{abstract}
Results: Survival after 1,3 , and 5 years postoperatively was $74.4 \%, 39.8 \%$, and $29.5 \%$, respectively. The independent predictive factors for increased postoperative survival were tumor recurrence rather than residual tumor as the indication for salvage surgery $(P<.001$; odds ratio [OR], 0.292); complete tumor resection $(P<.001$; OR, 4.520); $\mathrm{N}$ category $(P=.089 ; \mathrm{OR}, 1.304)$; $\mathrm{M}$ category $(P=.081 ; \mathrm{OR}, 2.215)$, and total mediastinal dissection with 15 or more dissected mediastinal lymph nodes $(P=.034$; OR, 0.546).

Conclusions: Salvage indications of recurrence, earlier disease, and complete tumor resection are related to longer survival. The total area of mediastinal dissection with a sufficient number of dissected mediastinal lymph nodes improves survival. Additional neck dissection does not add benefit. The optimal procedure for lymph node dissection in salvage esophagectomy should be established in future studies. (J Thorac Cardiovasc Surg 2014;147:1805-11)
\end{abstract}

The landmark RTOG 85-01 randomized trials clearly demonstrated that chemoradiotherapy (CRT) is a curative approach for squamous cell carcinoma. ${ }^{1}$ Although complete response rates are high and short-term survival is favorable after definitive CRT, locoregional tumor residual or recurrence is not uncommon. Therefore, with increasing experience, the number of salvage esophagectomies is expected to increase each year. Examples from the literature demonstrate potential long-term survival and increased morbidity and mortality after salvage esophagectomy, suggesting that a reduction in the extent of lymphadenectomy would be prudent. ${ }^{2}$ However, few articles have discussed the extent of lymph node dissection in salvage esophagectomy. The present study focused on survival after salvage esophagectomy for thoracic squamous cell carcinoma to

\footnotetext{
From the Division of Esophageal Surgery, ${ }^{\mathrm{a}}$ Department of Surgery, National Cancer Center Hospital, Tokyo, Japan; Department of Thoracic Surgery, ${ }^{\mathrm{b}}$ Huashan Hospital, Fudan University, Shanghai, China.

Disclosures: Authors have nothing to disclose with regard to commercial support.

Received for publication Sept 4, 2013; revisions received Dec 19, 2013; accepted for publication Dec 27, 2013; available ahead of print Feb 9, 2014.

Address for reprints: Yuji Tachimori, MD, Division of Esophageal Surgery, Department of Surgery, National Cancer Center Hospital, 5-1-1 Tsukiji, Chuo-ku, Tokyo 104-0045, Japan (E-mail: ytachimo@ncc.go.jp).

$0022-5223 / \$ 36.00$

Copyright (c) 2014 by The American Association for Thoracic Surgery

http://dx.doi.org/10.1016/j.jtcvs.2013.12.040
}

identify the prognostic factors for long-term survival using multivariate analysis and to provide evidence for the optimal extent of lymphadenectomy from a prognostic perspective.

\section{MATERIALS AND METHODS \\ Patients \\ Computerized and manual searches using the keyword "salvage esoph- agectomy" were conducted in our patient database, and 140 patients were found from the beginning of 1999 to the end of 2012. Thirteen patients with cervical carcinoma and 5 patients with abdominal or gastroesophageal junction carcinoma were excluded, as were 9 patients who underwent emergency salvage surgery or induction therapy before definitive CRT or other salvage therapy between definitive CRT and salvage esophagectomy. Nine in-hospital deaths were also excluded. The study population thus comprised 104 patients who underwent and survived salvage esophagec- tomy for thoracic esophageal carcinoma only after failure of definitive CRT (Figure 1). The present study was approved by the Institutional Re- view Board and individual consent for the study was waived.}

\section{Data Collection}

All patient data, including demographic characteristics, tumor location, histology, clinical and pathologic TNM stage, surgical features, and CRT features, were collected retrospectively. Staging was judged clinically before definitive CRT using the sixth edition of the Union for International Cancer Control (UICC) TNM classification system and pathologically after salvage surgery using the seventh edition of the UICC TNM classification system. The demographic and preoperative characteristics are summarized 


\section{Abbreviations and Acronyms}

CRT $=$ chemoradiotherapy

DFI $=$ disease-free interval

$\mathrm{OR}=$ odds ratio

ROC $=$ receiver operating characteristic

$\mathrm{UICC}=$ Union for International Cancer Control

in Table 1. Tumor histology was squamous cell carcinoma in all patients before definitive CRT.

\section{Chemoradiotherapy}

The details of definitive CRT with curative intent have been described elsewhere, ${ }^{3,4}$ Briefly, CRT consisted of 3 to 5 courses of cisplatin + fluorouracil and concomitant radiotherapy (50.4 to $70 \mathrm{~Gy}$ ) delivered over 6 to 7 weeks. We usually evaluated the effect of definitive CRT 1 month later after the final day of radiation. If the patient was evaluated as complete remission through endoscopic examination plus biopsy and computed tomography, we performed the same examination 1 month later. Patients who were evaluated as in complete remission again were regarded as true complete remission. Recurrence was defined as tumor regrowth after true complete remission with histologic confirmation. Residual tumor occurred when true complete remission was not achieved. In case of severe stricture or esophagitis, when biopsy was difficult, the patient was regarded as incomplete remission or stable disease from the result of computed tomography and positron emission tomography, and included in the residual tumor category.

\section{Surgical Considerations}

Salvage esophagectomy was administered to patients whose tumor persisted or recurred after definitive CRT. It did not include surgery after tumor downstaging or performance status improvement after neoadjuvant CRT. Salvage indication was local relapse without distant metastasis or massive lymph node metastasis. In brief, salvage surgery should be performed when curability can be anticipated to a certain degree. When resectability was uncertain, we tended to perform salvage surgery because there was no other curative therapy for these patients. In contrast, patients with distant metastasis, massive lymph node metastasis, apparent $\mathrm{T} 4$ disease, or poor performance status or very elderly patient were not considered for salvage esophagectomy, similar to the considerations for planned esophagectomy.

At our institute, right transthoracic subtotal esophagectomy with 3-field lymph node dissection was the standard procedure for esophageal carcinoma. However, mortality and morbidity were high during our initial experience with this operation used under salvage conditions. Therefore, some modifications were made to the surgical method, which included preservation of the bronchial artery and avoidance of neck dissection. ${ }^{2}$

In the present study, total mediastinal dissection, a term used to describe only the dissected area, was defined as dissection involving not only the middle and lower mediastinum but also the upper mediastinum. In detail, total mediastinal dissection involves, but is not limited to, the lymph nodes along the bilateral recurrent laryngeal nerves, paraesophageal nodes, posterior mediastinal nodes, aortopulmonary nodes, subcarinal nodes, bilateral pulmonary hilar nodes, and supradiaphragmatic nodes.

After complete salvage esophagectomy, no adjuvant therapy aiming to reduce the recurrent risk was administered to the patients. Chemotherapy, radiation, CRT, resection of enlarged metastatic lymph node, or endoscopic mucosa resection in cases of solitary local recurrence were used in 30 cases of recurrence or residual tumor after salvage esophagectomy.

\section{Follow-up}

The follow-up assessments were conducted by telephone and personal interviews until April 30, 2013. All patients were followed up, with a median follow-up time of 25.5 months. The clinical end point was survival status after salvage surgery.

\section{Statistical Methods}

Statistics were analyzed and relevant curves were created using the SPSS 13.0 Statistics Software Package (SPSS Inc., Chicago, Ill). Unless stated otherwise, mean values and standard deviations are reported. The Student $t$ test was used for comparisons between subgroups. For categorical

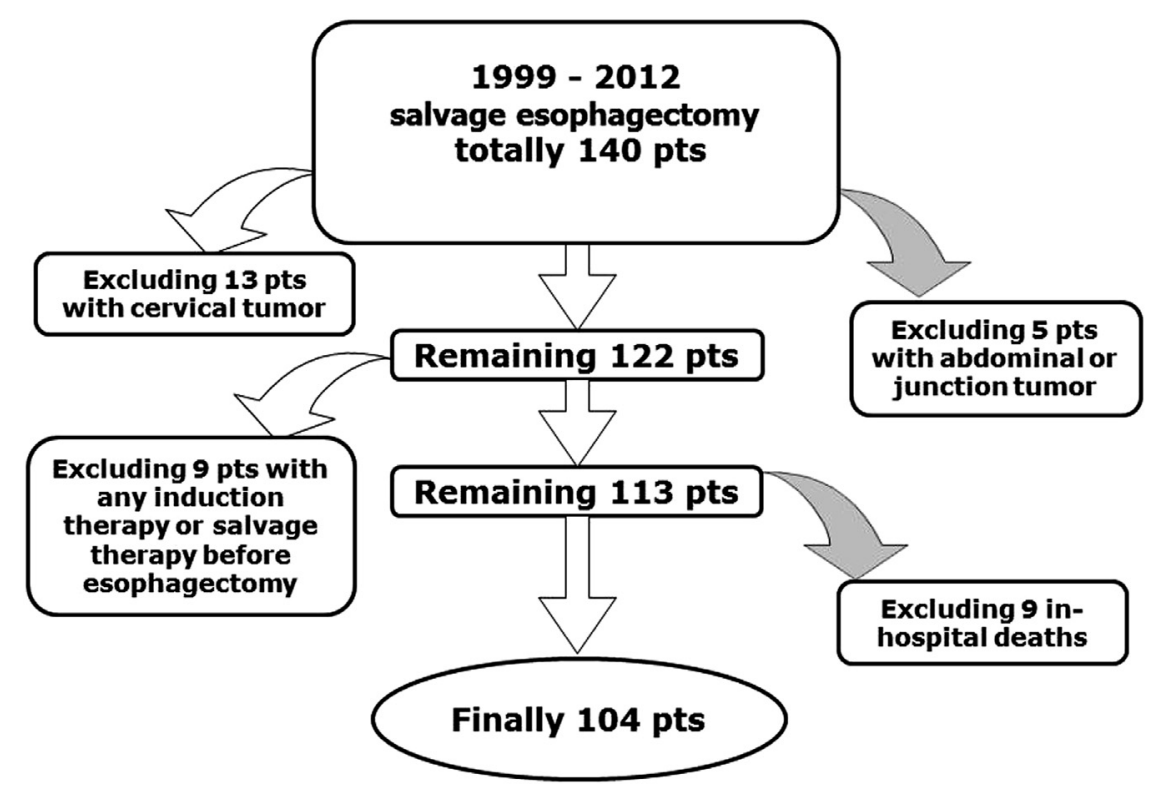

FIGURE 1. Consort diagram for patient selection. 
TABLE 1. Demographic and preoperative characteristics of 104 patients

\begin{tabular}{lc}
\hline \multicolumn{1}{c}{ Characteristic } & Value \\
\hline Age at operation, y \pm standard deviation & $62.6 \pm 7.8$ \\
Sex (male/female), $\mathrm{n}$ & $91 / 13$ \\
Tumor location in thorax (upper/middle/lower), $\mathrm{n}$ & $27 / 44 / 33$ \\
Stage judged clinically before dCRT (I/II/III/IV), $\mathrm{n}$ & $14 / 31 / 43 / 16$ \\
Complete response to dCRT, n (\%) & $38(36.5)$ \\
Esophagus-preserving interval after dCRT, mo (median) & $3-114(8)$ \\
\hline$d C R T$, Definitive chemoradiotherapy.
\end{tabular}

variables, the $\chi^{2}$ test or the Fisher exact test was used as appropriate. The optimal cut-off number of dissected lymph nodes for predicting increased survival was calculated by receiver operating characteristic (ROC) curve analysis. Survival curves were constructed using the Kaplan-Meier method, and the log-rank method was used for comparisons between curves. Variables with a $P$ value less than .1 were included in the multivariate analysis. A Cox proportional hazards model with the backward Wald method was used for multivariate analysis of postoperative survival. Those variables remaining in the Cox proportional hazards model at the last step were considered as independent risk factors.

\section{RESULTS}

Optimal Cut-Off Number of Dissected Lymph Nodes for Predicting Increased Survival

The results of ROC curve analysis (data not shown) showed that neither the curve for dissected mediastinal lymph node number $(P=.353)$ nor the curve for dissected total lymph node number $(P=.575)$ was significant to establish an optimal cut-off value. Therefore, from the results of the ROC curves, patients were arbitrarily grouped for the following prognostic analysis.

\section{Postoperative Survival and Predictors for Survival After Salvage Esophagectomy}

The actuarial survival 1,3 , and 5 years postoperatively was $74.4 \%, 39.8 \%$, and $29.5 \%$, respectively. Univariate analysis showed that tumor recurrence rather than residual tumor was the indication for salvage surgery (Figure 2, $P=.012)$. Lower M category $(P=.019)$, earlier TNM stage $(P=.001)$, complete tumor resection (Figure 3, $P<.001$ ), total mediastinal dissection $(P=.010)$, number of dissected mediastinal lymph nodes 15 or more $(P=.006)$, total mediastinal dissection with 15 or more dissected mediastinal lymph nodes (Figure 4, $P=.001$ ), and total number of dissected lymph nodes of 20 or more $(P=.014)$ were associated with increased postoperative survival (Table 2). Lower $\mathrm{T}$ category $(P=.070)$ and lower $\mathrm{N}$ category $(P=.057)$ were potential factors related to longer survival (Table 2). There was no significant difference in postoperative survival between patients receiving additional neck dissection and those without neck dissection $(P=.411)$.

The subsequent Cox proportional hazards model, the efficacy of which was determined using a $\chi^{2}$ test

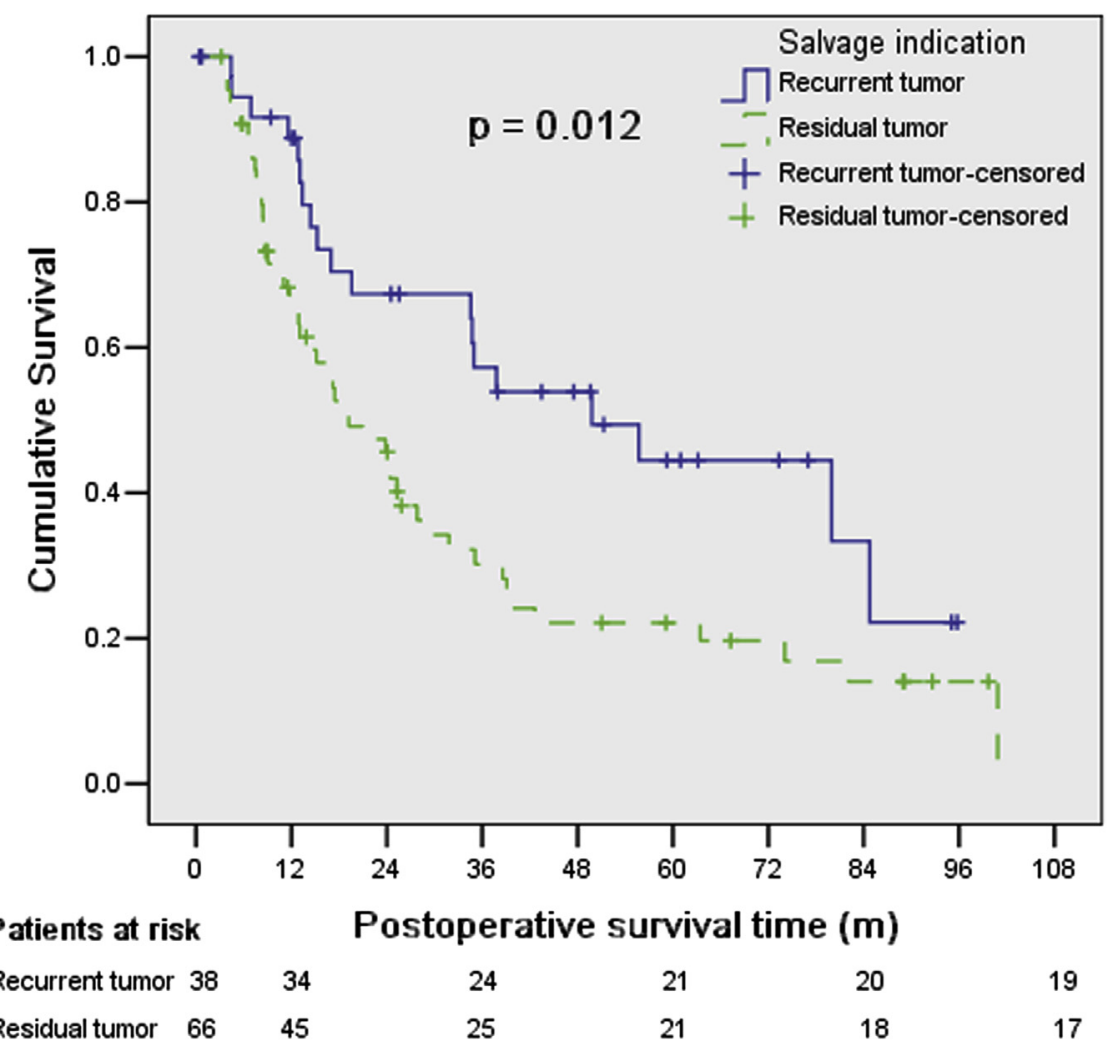

FIGURE 2. Comparison of Kaplan-Meier curves between subgroups with different salvage indications, $P=.012$. 


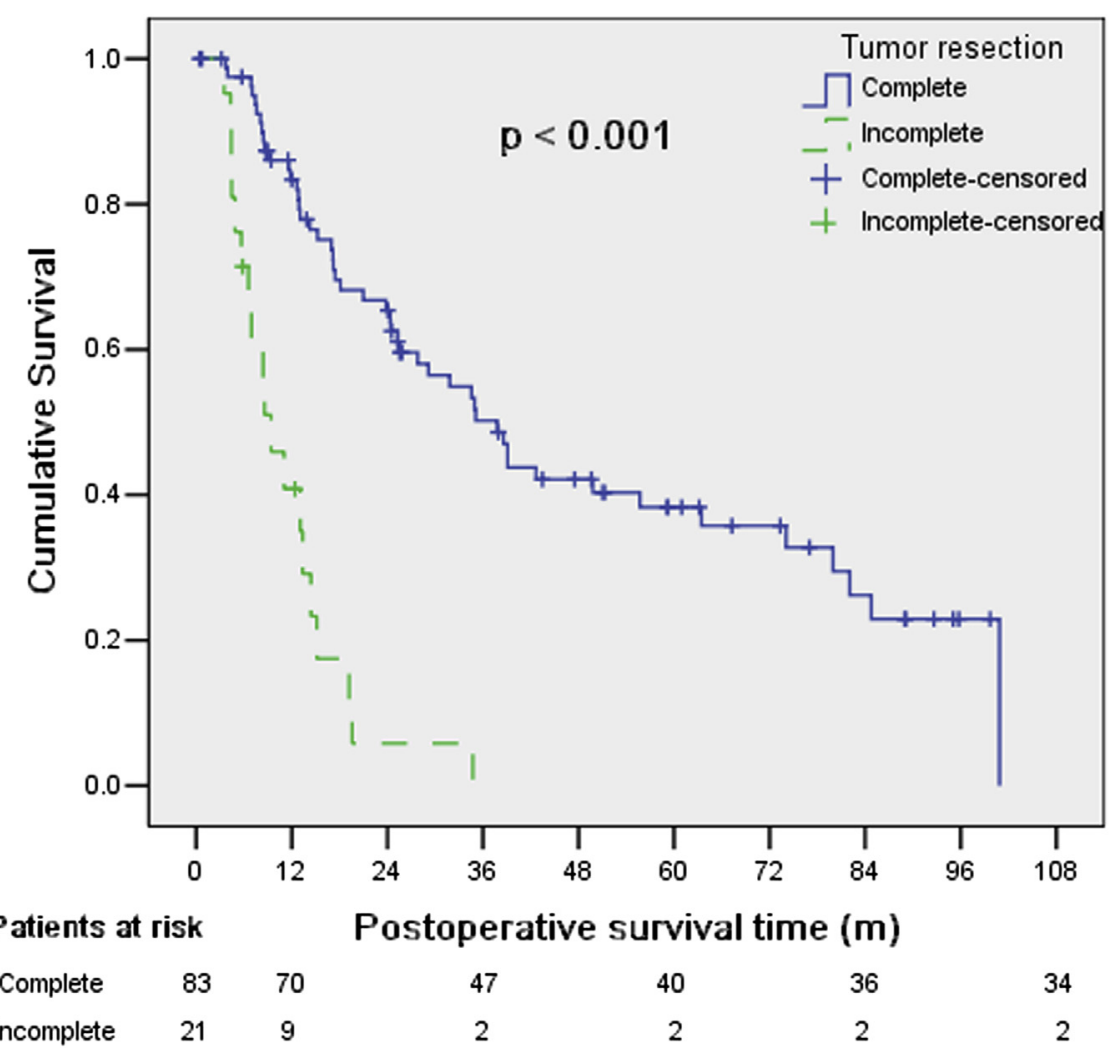

FIGURE 3. Comparison of Kaplan-Meier curves between complete resection (R0) and incomplete resection (R1/2), $P<.001$.

$\left(\chi^{2}=66.029, P<.001\right)$, demonstrated that tumor recurrence rather than residual tumor was the indication for salvage surgery $(P<.001$; odds ratio $[\mathrm{OR}], 0.292)$. Complete tumor resection $(P<.001 ; \mathrm{OR}, 4.520), \mathrm{N}$ category $(P=.089 ;$ OR, 1.304); M category $(P=.081$; OR, $2.215)$, and total mediastinal dissection with 15 or more dissected mediastinal lymph nodes $(P=.034$; OR, 0.546) were the independent predictive factors for survival after salvage esophagectomy (Table 2).

For 38 patients who underwent salvage esophagectomy for tumor recurrence, postoperative survival after 1, 3, and 5 years was $87.8 \%, 56.0 \%$, and $42.5 \%$, respectively; for 66 patients who underwent salvage esophagectomy for residual tumor, postoperative survival after 1,3 , and 5 years was $66.3 \%, 29.7 \%$, and $20.1 \%$, respectively (Figure 2, $P=.012)$.

For 83 patients who underwent complete tumor resection (R0 resection), postoperative survival after 1, 3, and 5 years was $83.1 \%, 49.7 \%$, and $36.9 \%$, respectively; for 21 patients who underwent incomplete tumor resection (R1/2 resection), postoperative survival after 1,3 , and 5 years was $38.0 \%, 4.1 \%$, and $0 \%$, respectively (Figure 3, $P<.001)$.

For 35 patients who underwent total mediastinal dissection with 15 or more mediastinal lymph nodes dissected, postoperative survival after 1,3 , and 5 years was $90.5 \%$,
$52.1 \%$, and $43.5 \%$, respectively; for 69 patients who underwent nontotal mediastinal dissection or with less than 15 mediastinal lymph nodes dissected, postoperative survival after 1,3 , and 5 years was $64.8 \%, 32.4 \%$, and $19.6 \%$, respectively (Figure $4, P=.001$ ).

\section{DISCUSSION}

It has been reported in the literature that the most significant predictive factor is complete resection without residual tumor (R0), ${ }^{5-7}$ which is confirmed by the present results. The 1- and 2-year survival after incomplete tumor resection was $38.0 \%$ and $4.1 \%$, respectively, consistent with the results reported in the literature. ${ }^{8,9}$ Only by complete resection can long-term survival be anticipated. ${ }^{10}$ Given the high postoperative morbidity and mortality after salvage esophagectomy and the poor prognosis with incomplete resection, in our opinion, the objective of salvage esophagectomy should be complete resection rather than incomplete resection. Therefore, preoperative evaluation of tumor resectability is important. However, accurate evaluation of the $\mathrm{T}$ factor in irradiated patients might be difficult preoperatively, even with the help of bronchoscopy and high-resolution computed tomography, ${ }^{7}$ and irradiated tissues are difficult to distinguish from tumor during surgery. Fibrosis is usually increased in radiation fields, and some cancer cells are likely to be left behind in the deep layer 


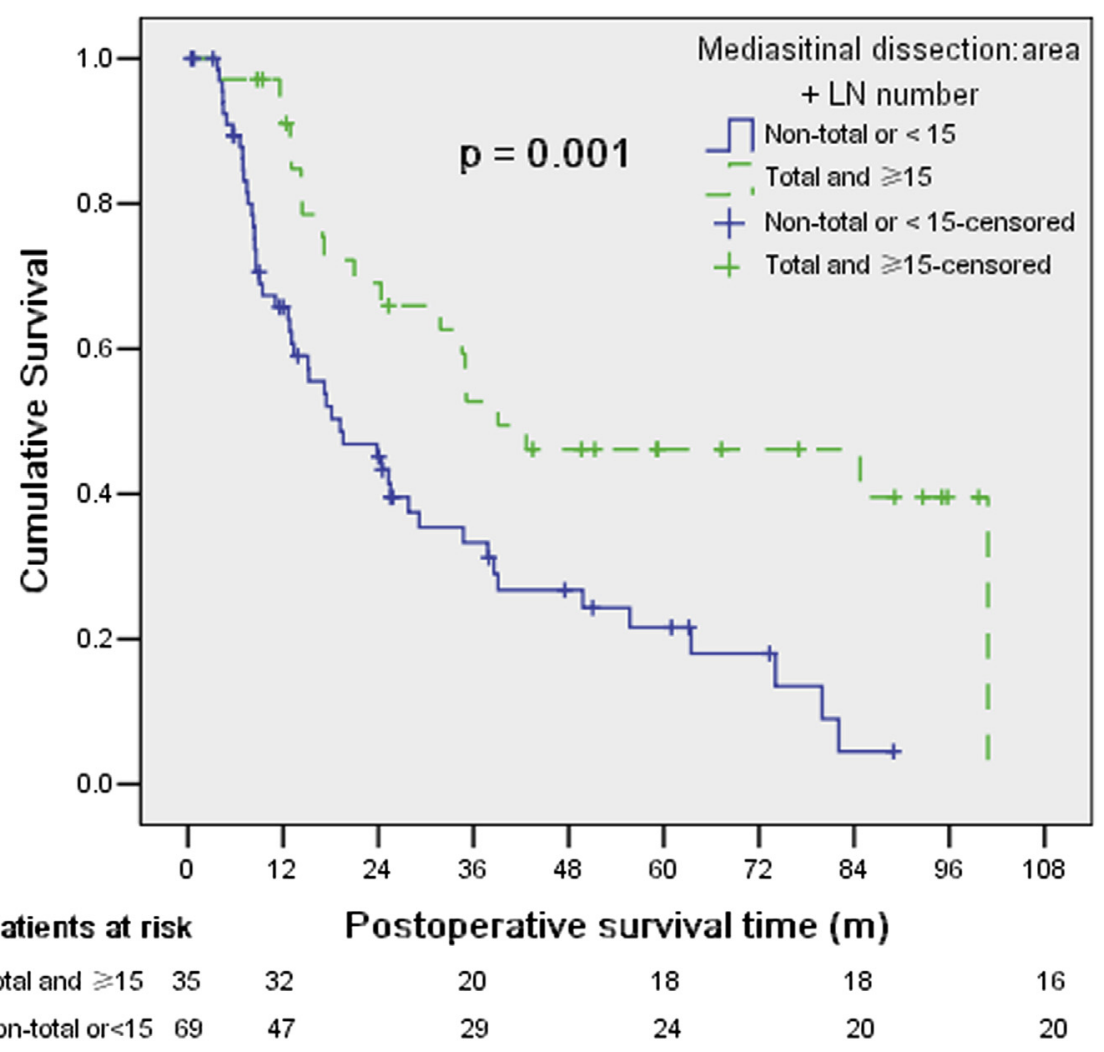

FIGURE 4. Comparison of Kaplan-Meier curves between total mediastinal dissection with more than 15 nodes dissected and nontotal mediastinal dissection or less than 15 mediastinal nodes dissected, $P=.001$.

of the esophageal wall after radiotherapy. In the present study, incomplete resection was due to a positive margin and tumor invasion in vital organs. Thus, patients should be carefully selected for salvage esophagectomy in experienced centers that specialize in esophageal cancer.

Few studies reported in the literature have addressed the optimal extent of lymph node dissection in salvage esophagectomy from a prognostic perspective. Our previous study demonstrated that neck dissection should be avoided to preserve the blood supply from the bronchial branch originating from the inferior thyroid artery, because of the high risk of a fatal airway fistula after salvage surgery. ${ }^{2}$ The present study shows that neck dissection is not justified on any statistical analysis; however, the area of mediastinal dissection, the number of mediastinal lymph nodes dissected, and the combination of area and number were demonstrated to be potential predictive factors on univariate analysis. The combination of area of mediastinal dissection and the number of mediastinal lymph nodes dissected was demonstrated to be one of the independent predictive factors for survival on Cox multivariate analysis. This can probably be explained by the fact that these 2 variables, the number and the area of mediastinal lymph nodes dissected, are correlated with each other and interrelated with complete resection; in patients undergoing incomplete resection, especially in those with macroscopic residual tumor, mediastinal dissection was more likely to have been precluded. However, when area and number were considered together, the effect of the combination on postoperative survival was independent of complete tumor resection. It is our view that the quality of mediastinal dissection should be evaluated by both the number of lymph nodes dissected and the mediastinal area dissected. During qualified mediastinal dissection, not only the lymph node vulnerable to metastasis but also the node with perceptible or imperceptible metastasis can be removed, which helps to reduce the risk of locoregional or distant recurrence, and thus improves actuarial survival after salvage esophagectomy. Therefore, the significance of mediastinal dissection should not be ignored. On the other hand, compared with mediastinal dissection in patients without previous definitive CRT, which is more aggressive and radical, mediastinal dissection in salvage esophagectomy is still considered conservative. Because of the variation in inflammatory changes caused by irradiation and the tumor location, lymphadenectomy in salvage esophagectomy after definitive CRT varies case by case. The optimal procedure for lymph node dissection in salvage esophagectomy that is both safe and effective has yet to be established. The present ROC curves failed 
TABLE 2. Univariate and multivariate analysis of prognostic factors for survival after salvage esophagectomy after definitive chemoradiotherapy

\begin{tabular}{|c|c|c|c|c|c|c|c|c|}
\hline \multirow[b]{2}{*}{ Variables } & \multicolumn{5}{|c|}{ Univariate analysis } & \multicolumn{3}{|c|}{ Multivariate analysis } \\
\hline & $\begin{array}{c}\text { Number } \\
\text { of cases }\end{array}$ & $\begin{array}{l}\text { Median } \\
\text { survival } \\
\text { (months) }\end{array}$ & $\begin{array}{c}\text { Standard } \\
\text { error } \\
\text { (months) }\end{array}$ & $\begin{array}{c}\mathbf{9 5} \% \text { confidence } \\
\text { interval } \\
\text { (months) }\end{array}$ & $\begin{array}{c}P \\
\text { value }\end{array}$ & $\begin{array}{c}P \\
\text { value }\end{array}$ & $\begin{array}{c}\text { Hazard } \\
\text { ratio }\end{array}$ & $\begin{array}{c}95 \% \text { confidence } \\
\text { interval for } \\
\text { hazard ratio }\end{array}$ \\
\hline Age & & & & & .954 & - & - & - \\
\hline$\geq 65 \mathrm{y}$ & 50 & 35.1 & 6.8 & $21.7-48.5$ & & & & \\
\hline$<65 \mathrm{y}$ & 54 & 21.0 & 4.1 & $12.9-29.0$ & & & & \\
\hline Sex & & & & & .334 & - & - & - \\
\hline Male & 91 & 24.4 & 5.9 & $12.8-36.0$ & & & & \\
\hline Female & 13 & 82.1 & 0.0 & - & & & & \\
\hline Tumor location & & & & & .372 & - & - & - \\
\hline Upper thorax & 27 & 17.2 & 3.2 & $10.8-23.5$ & & & & \\
\hline Middle thorax & 44 & 24.4 & 5.9 & $12.9-35.9$ & & & & \\
\hline Lower thorax & 33 & 37.8 & 13.3 & $11.8-63.8$ & & & & \\
\hline Irradiation dose & & & & & .421 & - & - & - \\
\hline$\geq 60$ Gy & 85 & 27.8 & 5.4 & $17.3-38.3$ & & & & \\
\hline$<60 \mathrm{~Gy}$ & 19 & 18.1 & 2.4 & $13.3-22.9$ & & & & \\
\hline Salvage indication & & & & & .012 & $<.001$ & 0.292 & $0.167-0.513$ \\
\hline Tumor recurrence & 38 & 49.8 & 14.9 & $20.6-79.0$ & & & & \\
\hline Residual tumor & 66 & 19.2 & 3.8 & $11.8-26.6$ & & & & \\
\hline $\mathrm{T}$ category (judged pathologically) & & & & & .070 & .549 & - & - \\
\hline $\mathrm{T} 0$, is & 10 & 53.5 & 10.5 & $32.8-74.1$ & & & & \\
\hline $\mathrm{T} 1$ & 17 & 64.4 & 25.9 & $13.7-115.1$ & & & & \\
\hline $\mathrm{T} 2$ & 15 & 30.1 & 4.2 & $21.8-38.4$ & & & & \\
\hline $\mathrm{T} 3$ & 55 & 31.6 & 5.7 & $20.4-42.8$ & & & & \\
\hline $\mathrm{T} 4$ & 7 & 15.0 & 0.5 & $14.0-16.0$ & & & & \\
\hline $\mathrm{N}$ category (judged pathologically) & & & & & .057 & .089 & 1.304 & $0.961-1.771$ \\
\hline N0 & 68 & 60.7 & 14.1 & $33.0-88.4$ & & & & \\
\hline N1 & 24 & 26.1 & 0.8 & $24.5-27.7$ & & & & \\
\hline $\mathrm{N} 2$ & 8 & 27.9 & 5.8 & $16.6-39.2$ & & & & \\
\hline N3 & 4 & 24.6 & 13.4 & $0.0-50.9$ & & & & \\
\hline M category (judged pathologically) & & & & & .019 & .081 & 2.215 & $0.906-5.413$ \\
\hline M0 & 97 & 40.1 & 7.2 & $26.0-54.2$ & & & & \\
\hline M1 & 7 & 23.3 & 10.9 & $1.9-44.7$ & & & & \\
\hline TNM stage (judged pathologically) & & & & & .001 & .326 & - & - \\
\hline 0 & 8 & 53.5 & 8.7 & $36.4-70.5$ & & & & \\
\hline I & 19 & 64.4 & - & - & & & & \\
\hline II & 41 & 60.7 & 23.5 & $14.7-106.7$ & & & & \\
\hline III & 29 & 26.1 & 3.7 & $18.9-33.3$ & & & & \\
\hline IV & 7 & 23.3 & 10.9 & $1.9-44.7$ & & & & \\
\hline Tumor resection & & & & & $<.001$ & $<.001$ & 4.520 & $2.480-8.237$ \\
\hline Complete (R0) & 83 & 37.8 & 4.7 & $28.6-47.0$ & & & & \\
\hline Incomplete (R1/2) & 21 & 9.4 & 1.9 & $5.6-13.2$ & & & & \\
\hline Neck dissection & & & & & .411 & - & - & - \\
\hline With & 20 & 34.9 & 12.9 & $9.6-60.2$ & & & & \\
\hline Without & 84 & 25.3 & 5.3 & $15.0-35.6$ & & & & \\
\hline Area of mediastinal dissection & & & & & .010 & .565 & - & - \\
\hline Total & 76 & 34.6 & 6.8 & $21.3-47.8$ & & & & \\
\hline Nontotal & 28 & 15.1 & 5.5 & $4.4-25.8$ & & & & \\
\hline Number of mediastinal lymph nodes dissected & & & & & .006 & .133 & - & - \\
\hline$\geq 15$ & 38 & 35.1 & 6.1 & $23.1-47.1$ & & & & \\
\hline$<15$ & 66 & 19.2 & 5.1 & $9.2-29.2$ & & & & \\
\hline Mediastinal dissection: area + number of lymph nodes & & & & & .001 & .034 & 0.546 & $0.312-0.955$ \\
\hline Total $+\geq 15$ & 35 & 39.1 & 27.0 & $0.0-92.1$ & & & & \\
\hline Nontotal or $<15$ & 69 & 19.2 & 4.8 & $9.8-28.6$ & & & & \\
\hline Number of totally dissected lymph nodes & & & & & .014 & .804 & - & - \\
\hline$\geq 20$ & 62 & 34.9 & 8.3 & $18.7-51.2$ & & & & \\
\hline$<20$ & 42 & 19.2 & 5.3 & $8.9-29.5$ & & & & \\
\hline
\end{tabular}


to yield a best cut-off value for the number of lymph nodes dissected for predicting longer survival. Therefore, based on the current results, it can only be concluded that both mediastinal dissection area and the number of mediastinal lymph nodes dissected are important for improving survival. The more detailed extent of lymph node dissection and the specific number of dissected lymph nodes for optimal lymphadenectomy, however, should be established in future studies.

Eight patients (7.69\%) with pathologic stage 0 underwent salvage surgery, which was comparable with the literature $(12.5 \%){ }^{10}$ These 8 patients were in the residual tumor group, and 1 of the patients had carcinoma in situ. For patients with signs of persistent tumor on computed tomography or positron emission tomography but without histologic confirmation, despite the heterogeneity of the cohort, we still believed that it was not ethical to delay salvage surgery until we had histologic evidence. Some patients would have lost the chance of surgery if we had waited.

The most recent literature has shown that the 3-year and 5 -year postoperative survival after salvage esophagectomy ranged from $17 \%$ to $58 \%$ and $17 \%$ to $33 \%$, respectively. ${ }^{6-13}$ The present results showed that postoperative survival after 1,3 , and 5 years was $74.4 \%, 39.8 \%$, and $29.5 \%$, respectively. The difference in reported survival can be explained by the different patient enrollment criteria: (1) most studies enrolled patients with locally advanced esophageal carcinoma, whereas the present study included those with stage I tumors (judged clinically) who were registered in the Japanese Clinical Oncology Group Study (JCOG 9708) ${ }^{4}$ evaluating the efficacy of definitive CRT in stage I esophageal squamous cell carcinoma at our institution; and (2) the proportion of patients with adenocarcinoma was different. In our institute, squamous cell carcinoma is the only indication for definitive CRT. Apart from the difference in the enrollment criteria, the difference in surgical features is also worth examining. Compared with transhiatal esophagectomy, transthoracic esophagectomy is more curative with regard to mediastinal lymph node dissection, as has been demonstrated by the present study.

There is some evidence of a more favorable cancer prognosis if salvage esophagectomy is done for recurrent rather than for persistent disease, ${ }^{5}$ which was confirmed by the present results. A complete response to definitive CRT means not only complete remission of the primary lesion and the metastatic regional lymph nodes but also success in treating potential intramural and regional metastases. Therefore, recurrence risk is reduced and prognosis is improved after salvage surgery. The recurrence group (with a longer disease-free interval [DFI]) had better survival than the persistent group (with a shorter DFI). On further statistical analysis, however, the ROC curve failed to give the best cut-off for DFI predicting better survival (area $=0.450, P=.414)$. Similarly, $\mathrm{ROC}$ is not significant to establish the best cut-off, but longer DFI is significant for predicting better survival.

Because this was a retrospective study for esophageal squamous cell carcinoma, and, consequently, selective bias and heterogeneity of the patients could not be completely averted, the present findings should be interpreted with caution, especially in western countries where adenocarcinoma is the dominant histologic type. The cutoff value for the number of mediastinal lymph nodes dissected, which could not be established on ROC curve analysis $(P>.05)$, was somewhat arbitrary.

Based on the results, we conclude that a complete response to definitive CRT, earlier disease, and complete tumor resection are related to increased survival. Total mediastinal dissection with a sufficient number of dissected mediastinal lymph nodes improves postoperative survival. Additional neck dissection dose not add benefit. The optimal procedure for lymph node dissection in salvage esophagectomy after definitive CRT should be established in future studies.

\section{References}

1. Cooper JS, Guo MD, Herskovic A, Macdonald JS, Martenson JA, Al-Sarraf M, et al. Chemoradiotherapy of locally advanced esophageal cancer: long-term follow-up of a prospective randomized trial (RTOG 85-01). Radiation Therapy Oncology Group. JAMA. 1999;281:1623-7.

2. Tachimori Y, Kanamori N, Uemura N, Hokamura N, Igaki H, Kato H. Salvage esophagectomy after high-dose chemoradiotherapy for esophageal squamous cell carcinoma. J Thorac Cardiovasc Surg. 2009;137:49-54.

3. Kato K, Muro K, Minashi K, Ohtsu A, Ishikura S, Boku N, et al; Gastrointestinal Oncology Study Group of the Japan Clinical Oncology Group (JCOG). Phase II study of chemoradiotherapy with 5-fluorouracil and cisplatin for Stage II-III esophageal squamous cell carcinoma: JCOG trial (JCOG 9906). Int J Radiat Oncol Biol Phys. 2011;81:684-90.

4. Kato H, Sato A, Fukuda H, Kagami Y, Udagawa H, Togo A, et al. A phase II trial of chemoradiotherapy for stage I esophageal squamous cell carcinoma: Japan Clinical Oncology Group Study (JCOG9708). Jpn J Clin Oncol. 2009;39: 638-43

5. Smithers BM, Cullinan M, Thomas JM, Martin I, Barbour AP, Burmeister BH, et al. Outcomes from salvage esophagectomy post definitive chemoradiotherapy compared with resection following preoperative neoadjuvant chemoradiotherapy. Dis Esophagus. 2007;20:471-7.

6. Chao YK, Chan SC, Chang HK, Liu YH, Wu YC, Hsieh MJ, et al. Salvage surgery after failed chemoradiotherapy in squamous cell carcinoma of the esophagus. Eur J Surg Oncol. 2009;35:289-94.

7. Tomimaru Y, Yano M, Takachi K, Miyashiro I, Ishihara R, Nishiyama K, et al Factors affecting the prognosis of patients with esophageal cancer undergoing salvage surgery after definitive chemoradiotherapy. J Surg Oncol. 2006;93:422-8.

8. Morita M, Kumashiro R, Hisamatsu Y, Nakanishi R, Egashira A, Saeki H, et al. Clinical significance of salvage esophagectomy for remnant or recurrent cancer following definitive chemoradiotherapy. J Gastroenterol. 2011;46:1284-91.

9. Tachimori Y. Role of salvage esophagectomy after definitive chemoradiotherapy. Gen Thorac Cardiovasc Surg. 2009;57:71-8.

10. D'Journo XB, Michelet P, Dahan L, Doddoli C, Seitz JF, Giudicelli R, et al. Indications and outcome of salvage surgery for oesophageal cancer. Eur J Cardiothorac Surg. 2008;33:1117-23.

11. Schieman C, Wigle DA, Deschamps C, Nichols FC III, Cassivi SD, Shen KR, et al. Salvage resections for recurrent or persistent cancer of the proximal esophagus after chemoradiotherapy. Ann Thorac Surg. 2013;95:459-63.

12. Yoo C, Park JH, Yoon DH, Park SI, Kim HR, Kim JH, et al. Salvage esophagectomy for locoregional failure after chemoradiotherapy in patients with advanced esophageal cancer. Ann Thorac Surg. 2012;94:1862-8.

13. Nishimura M, Daiko H, Yoshida J, Nagai K. Salvage esophagectomy following definitive chemoradiotherapy. Gen Thorac Cardiovasc Surg. 2007;55:461-5. 